\title{
XX Congreso Chileno de Infectología
}

\section{La Serena 5-8 de Noviembre 2003}

\section{Invitados internacionales:}

Pedro Cahn. Buenos Aires, Argentina. Área de mayor interés: SIDA

Franklin R. Cockerill. Mayo Clinic, Rochester E.U.A. microbiólogo. Área de mayor interés: técnicas de biología molecular.

Kieren A. Marr. Fred Hutchinson Cancer Research Center, Seattle, Washington. Área de mayor interés: infecciones en inmunocomprometidos.

Michele Pearson. Centers for Disease Control and Prevention, Atlanta; Georgia, E.U.A.. Experta en infecciones nosocomiales.

David Salisbury. Department of Health, Londres, Reino Unido. Experto en programas de inmunizaciones.

\section{Programa Científico}

\section{Miércoles 5}

\section{Curso Precongreso}

\section{Actualizaciones en vacunas}

Vacunas en mujeres embarazadas y en senescentes.

Vacuna antirábica.

Epidemiología molecular - Vigilancia en Chile.

Tipos de vacuna y esquemas.

Consultas frecuentes en inmunizaciones.

\section{Curso Precongreso}

Nutrición parenteral total:

Complicaciones infecciosas

Epidemiología.

Centralización, automatización y otros dilemas.

Calidad y seguridad.

Mesa redonda: Programa nacional de acreditación.

\section{Conferencia inaugural}

Vacunaciones: Estrategias comunicacionales para el público y profesionales de la salud.

\section{Jueves 6}

\section{Consenso}

Mejor tratamiento para Streptocccus pneumoniae resistente: Otitis media y sinusitis aguda, neumonía.

\section{Comunicaciones orales y posters}

\section{Conferencias}

Vacuna trivírica: inquietudes sobre su seguridad. Diagnóstico de bacterias emergentes.

\section{Controversias en corticoterapia}

Shock séptico.

Infecciones del SNC.

¿Corticoides o antimicrobianos?

Controversias en interpretación clínica de:

Cultivo de heridas.

Urocultivo.

Cultivo de tejidos a trasplantar.

\section{Jornada de Infecciones Intrahospitalarias}

Reutilización de material desechable

¿Por qué promover su discusión?

Áreas de mayor riesgo.

Reutilización y seguridad.

Simposios.

\section{Simposio}

Vigilancia de resistencia antimicrobiana en Chile

Estandarización de los estudios in vitro.

Modelos de vigilancia.

Informe preliminar de la red nacional. 


\section{Simposio}

Infección por virus de inmunodeficiencia humana

Latinoamérica y la terapia anti retroviral.

Novedades en fármacos.

Manejo de la toxicidad de anti retrovirales.

\section{Viernes 7}

\section{Conversaciones con expertos}

Infecciones en el viajero.

Endocarditis infecciosa en Pediatría.

Infección por VIH/SIDA.

\section{Simposio}

\section{Nuevos patógenos en Chile}

Ehrlichiosis.

SARS y otros virus respiratorios emergentes.

Calicivirus humanos.

\section{Simposio}

Inmunocompromiso e infecciones fúngicas invasoras

Epidemiología.

Novedades en diagnóstico.

Novedades terapéuticas.

\section{Comunicaciones orales y posters}

\section{Conferencia}

Amplificación génica en tiempo real: utilidad clínica.

\section{Simposio}

\section{Farmacoeconomía en Infectología}

Conceptos y aplicaciones.

Experiencia con vacuna conjugada anti meningocóccica $\mathrm{C}$.

\section{Sábado 8}

\section{Conversaciones con expertos}

Sífilis congénita.

Infecciones no meníngeas del SNC en adultos.

\section{Consenso}

Diarrea asociada a Clostridium difficile:

diagnóstico y tratamiento.

\section{Controversias en antibioterapia abreviada}

Infecciones osteoarticulares. Infecciones respiratorias altas. Vigencia de azitromicina.

\section{Controversias en síndrome disentérico}

Pacientes pediátrico: ¿tratar o no?

Enfrentamiento en el adulto.

Fundamentos de la antibioterapia.

\section{Simposio}

Enterococcus resistente a vancomicina

Epidemiología y control.

Diagnóstico molecular versus tradicional.

Tratamiento antimicrobiano.

\section{Simposio}

\section{Vacunas en huéspedes inmunocomprometidos}

En pacientes onco-hematológicos.

En pacientes infectados por VIH.

En esplenectomizados y bajo inmunosupresores.

\section{Conferencia de clausura}

Fiebre y neutropenia. 